1 Universidade Federal do Rio Grande do Sul (UFRGS) - Porto Alegre (RS), Brasil. rcristianne@gmail.com

2 University of Saskatchewan: Saskatoon (uSask) -Saskatoon (SK), Canadá.

3 Universidade Federal de Minas Gerais (UFMG)

- Belo Horizonte (MG) Brasil.

\section{Saúde para todos: a participação da sociedade civil na governança global em saúde}

\author{
Health for all: civil society participation in global health governance
}

Cristianne Maria Famer Rocha', Mariana da Rosa Martins², Mateus Aparecido de Farias $\mathbf{3}$

DOI: 10.1590/0103-11042020S114

RESUMO Os movimentos sociais, elementos fundamentais na luta pela implementação e manutenção de sistemas de saúde universais e na defesa do direito à saúde para todos, têm sua atuação ampliada no contexto da crise econômica mundial. A globalização traz um desafio à sociedade civil, o de engajar atores na formulação de políticas cujo alcance vai além do âmbito local. Este trabalho analisa as possibilidades de influência da sociedade civil nos processos decisórios da governança global na Organização Mundial da Saúde (OMS), através da abordagem do Observatório da OMS (WHO Watch), iniciativa do Movimento pela Saúde dos Povos (MSP), que se propõe a estimular a democratização dos processos decisórios da OMS. Como subsídio para as reflexões, são utilizadas as experiências do WHO Watch em três ocasiões: a $67^{\mathrm{a}}$ Assembleia Mundial de Saúde, a 53 ${ }^{\mathrm{a}}$ Reunião do Conselho Diretor da Organização Pan-americana da Saúde e a $136^{\text {a }}$ Reunião do Conselho Executivo da OMS. Conclui-se que os movimentos sociais trazem uma visão crítica sobre as discussões realizadas por esses órgãos intergovernamentais, promovendo a divulgação desses debates e de seus desdobramentos para além dos espaços governamentais.

PALAVRAS-CHAVE Sociedade civil. Saúde global. Organização Mundial da Saúde.

\begin{abstract}
Social movements, fundamental elements in the struggle for the implementation and maintenance of universal health systems and in the defence of the right to health for all, have been expanded in the context of the global economic crisis. Globalization brings a challenge to civil society, in engaging actors in formulating outreach policies that go beyond the local scope. This paper analyzes the possibilities of the influence of civil society over the decision-making processes of global governance in the World Health Organization (WHO), through the case of the WHO Watch, an initiative of the People's Health Movement (PHM) to stimulate the democratization of WHO's decision-making processes. The experiences of WHO Watch on three occasions are used as subsidy for reflection: the 67th World Health Assembly, the 53rd Meeting of the Directing Council of the Pan American Health Organization and the 136th Meeting of the WHO Executive Board. It is concluded that the social movements bring a critical view on the discussions carried out by these intergovernmental bodies, promoting the dissemination of these debates and their unfoldings beyond the governmental spaces.
\end{abstract}

KEYWORDS Civil society. Global health. World Health Organization. 


\section{Introdução}

As mudanças nas dinâmicas da economia global, que há alguns anos vêm acontecendo de maneira turbulenta, têm criado e aprofundado inequidades em saúde e em seus determinantes sociais. As políticas de austeridade -que consistem em um controle de gastos públicos, através de cortes em políticas sociais vêm constituindo-se em ameaças ao acesso universal aos serviços de saúde em diversos países, muitos dos quais foram aconselhados por organismos internacionais, como o Fundo Monetário Internacional (FMI), a reformarem seus sistemas de saúde ${ }^{\mathbf{1}}$. Em situações de contenção orçamentária, as políticas sociais geralmente são as primeiras a sofrer cortes ${ }^{2}$.

A ajuda internacional de organismos como o Banco Mundial e o FMI, instituições promotoras de políticas neoliberais, não mitiga esse efeito. Pelo contrário, seus empréstimos vêm condicionados a cláusulas que incluem o desmantelamento do setor público ${ }^{3}$ e um menor investimento em políticas públicas com drásticas reduções em gastos sociais estatais e privatizações $^{4}$. Dessa forma, é possível afirmar que o direito humano à saúde, que nunca se efetivou plenamente em um contexto global, está seriamente ameaçado, à medida que a contenção orçamentária resultaria em diminuição dos gastos públicos em saúde.

A Declaração de Alma-Ata ${ }^{5}$ entende a saúde como um direito humano fundamental e estabeleceu como meta a efetivação desse direito a todos até o ano 2000, não obtendo êxito. Ocorreu, também, no ano 2000, a realização da Assembleia Geral das Nações Unidas (ONU), que definiu os Objetivos de Desenvolvimento do Milênio (ODM), um compromisso assumido por todos os seus Estados-Membros, em temas como o combate à pobreza, à fome, à degradação ambiental, à discriminação contra as mulheres, entre outros ${ }^{6}$. Os ODM eram interdependentes entre si: todos os temas influenciavam a saúde e vice-versa ${ }^{7}$. $O$ ano marco para os ODM foi 2015, e, mais uma vez, apesar de avanços, os países não conseguiram alcançar as condições assumidas. A discussão agora gira em torno da Agenda Pós-2015 - ou Agenda 2030 - e dos Objetivos de Desenvolvimento Sustentáveis (ODS), que também incluem temas relacionados à saúde $\mathbf{1}^{\mathbf{1 , 8}, \mathbf{9}}$.

Um tema que não perde sua relevância, ao longo de décadas de discussão sobre a saúde, é o de como garantir que as decisões tomadas por governos e pelos órgãos intergovernamentais tenham como principal objetivo ir ao encontro das reais necessidades da população. Para tanto, a participação da sociedade civil nos espaços de tomada de decisão é fundamental. Imbuída desse entendimento, nasce a iniciativa Democratising Global Health Governance (em tradução livre: Democratizando a Governança Global em Saúde), do Movimento pela Saúde dos Povos (MSP), no qual está inserido o WHO Watch (em tradução livre: Observatório da OMS $)^{10}$. O WHO Watch propicia que observadores da sociedade civil participem das principais reuniões da Organização Mundial da Saúde (OMS) e de seus escritórios regionais. Foi a realização de três edições do WHO Watch que motivou a realização deste ensaio, que busca refletir sobre as potencialidades e os limites da participação dos movimentos sociais nos processos decisórios da governança global em saúde.

\section{A governança global em saúde e a participação da sociedade civil}

As questões contemporâneas de saúde de um determinado local estão cada vez mais conectadas e relacionadas àquelas de outros lugares e às decisões tomadas nas mais diversas escalas (local, nacional e internacional). Dá-se o nome de saúde global ao ramo da diplomacia que se refere aos temas de saúde que transcendem fronteiras nacionais e governos e demandam intervenções nas forças e nos fluxos globais que determinam a saúde das pessoas ${ }^{\mathbf{1 1}}$. Ainda, segundo os mesmos autores, esse novo cenário 
requer novas formas de governança nos níveis nacional e internacional, incluindo uma ampla gama de atores.

A saúde global exige esforços coordenados no manejo das questões nacionais, assumindo uma responsabilidade coletiva pela saúde ${ }^{\mathbf{2}}$. Ao unir as disciplinas de Saúde Pública, Relações Internacionais, Gestão, Direito e Economia, o termo Diplomacia da Saúde Global interpreta os processos de negociações, níveis e atores múltiplos que moldam e dirigem o ambiente da política global da saúde ${ }^{13}$.

Fidler ${ }^{\mathbf{1 4}}$, por sua vez, conceitua governança global em saúde como o uso de instituições formais e informais, regras e processos pelos Estados, organizações intergovernamentais e atores não estatais para lidar com desafios para a saúde que requerem ações transfronteiriças coletivas para serem resolvidos eficazmente.

O funcionamento das dinâmicas da governança global em saúde tem sido alvo de críticas por seus processos serem conduzidos por governos e agentes não estatais dos países mais ricos, que acabam, também, ocupando a maior parte dos cargos nos organismos multilaterais $^{\mathbf{1 5}}$. Gostin e Mok ${ }^{\mathbf{1 6}}$ defendem que a governança precisa enfrentar desafios que têm impedido a melhoria da saúde global e a diminuição das suas disparidades, como a ausência de uma liderança global, a necessidade de colaboração e coordenação de múltiplos atores e a insuficiência do financiamento, e pedem por maior transparência, monitoramento e accountability.

No que tange à questão do financiamento da OMS, o 'Global Health Watch 4', Relatório de Saúde elaborado por seis organizações da sociedade civil (MSP, Medact, Medico International, Third World Network, Health Action International e Asociación Latinoamericana de Medicina Social), analisa as receitas da OMS a partir das contribuições realizadas pelos Estados-Membros da Organização e mostra o desequilíbrio existente entre as contribuições obrigatórias e as contribuições voluntárias, um cenário distinto daquele de trinta anos atrás. Nos últimos anos, o Relatório mostra que ocorreu um aumento das contribuições voluntárias, enquanto que as obrigatórias foram reduzidas. As contribuições obrigatórias são definidas através de um cálculo que considera a população e o Produto Interno Bruto de cada país. No ano de 2012, as contribuições obrigatórias injetaram uma quantia de $\$ 475.000 .000$ (quatrocentos e setenta e cinco milhões de dólares americanos) na OMS. No mesmo ano, as contribuições voluntárias atingiram o valor de \$1.539.000.000 (um trilhão e quinhentos e trinta e nove milhões de dólares americanos), sendo que, desse total, \$1.409.000.000 (um trilhão, quatrocentos e nove milhões de dólares americanos) estavam atrelados a projetos escolhidos pelos doadores. Esses dados evidenciam um desafio à governança por conta da perda de autonomia, já que as doações obrigatórias financiam os projetos deliberados pelos foros decisórios da OMS, enquanto que as contribuições voluntárias, em sua quase totalidade, são atreladas a projetos específicos, não sendo, necessariamente, prioritários à Organização.

Em um cenário de crise financeira e de balança desigual de poder na governança global em saúde, foram iniciadas, em 2015, as discussões relativas à Reforma da OMS, processo que pretende implementar modificações programáticas, de governança e de gerência ${ }^{7}$. Os movimentos sociais, nesse contexto de alteração das estruturas de governança global da saúde, são elementos vitais na luta pela manutenção e pela implementação de sistemas de saúde universais e na defesa do direito à saúde para todos.

Assim, engajar atores na formulação de políticas de alcance global, que vão além do âmbito local, passa a ser um novo desafio para a sociedade civil. Os movimentos sociais têm que reunir questões de diversas comunidades e encontrar maneiras de apresentar propostas nos níveis nacional e internacional, o que envolve uma capacidade de se organizar em rede globalmente ${ }^{11}$. Kickbush e Berger ${ }^{\mathbf{1 3}}$ alertam,ainda,para a necessidade do envolvimento de diversos profissionais na diplomacia 
da saúde, que não é mais restrita a diplomatas ou mesmo a atores governamentais. Para tanto, esclarecem sobre a necessidade de desenvolvimento conceitual e de programas práticos de treinamento que permitam o desenvolvimento das habilidades de negociação que o atual cenário da saúde exige.

\section{O Movimento pela Saúde dos Povos e o WHO Watch}

O MSP é uma rede global de ativistas e organizações que atua na defesa da saúde como um direito e está presente em mais de setenta países, trabalhando com foco na atenção primária e nos determinantes sociais, econômicos e políticos da saúde. O MSP busca ser um condutor de mudanças, implementando ações caracterizadas por intervenções comunitárias, mobilização e resistência relacionadas à saúde e empreendendo advocacy global, baseado na solidariedade internacional, na formação de redes e na cooperação para lutar em prol de mudanças compartilhadas que surgem do processo neoliberal de globalização, sendo uma ponte entre o global e o local ${ }^{17}$.

Os princípios e as diretrizes do MSP estão

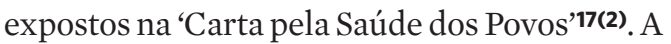
Carta explicita a "saúde como questão social, econômica e política e, acima de tudo, um direito humano fundamental". Dessa forma, o MSP defende, perante o governo e outras agências de saúde, a garantia do acesso universal aos cuidados de saúde, à educação e a serviços sociais de qualidade e em conformidade às necessidades das pessoas, não à sua capacidade de pagar pelo serviço.

Um dos projetos desenvolvidos pelo MSP é o WHO Watch (Observatório da OMS), que tem entre seus objetivos promover a democratização dos processos decisórios da OMS através da participação de ativistas como observadores nas reuniões em Genebra e nas regionais da Organização, da aproximação com os representantes nacionais na OMS, da análise dos tópicos discutidos nas reuniões, da produção de pareceres relativos às pautas e da divulgação e publicização das decisões tomadas no âmbito da OMS ${ }^{18}$.

A criação desse projeto ocorreu em função do entendimento de que as estruturas da governança global em saúde estão dominadas por grandes potências e por corporações transnacionais, mas que as relações de poder em torno das decisões globais - que influenciam a saúde das populações - são capazes de mudar essa situação através de novas alianças e novos fluxos de informação. Assim foi pensada a iniciativa Democratising Global Health Governance (Democratizando a Governança Global em Saúde), na qual está inserido o WHO Watch'.

Com o apoio de outros ativistas, que atuam presencialmente e também à distância, esses observadores ficam responsáveis, entre outras ações, pela produção de análises críticas dos principais pontos de pauta das reuniões. Essas análises começam a ser elaboradas ao longo dos meses que antecedem as reuniões, geralmente com consultas a ativistas que compõem os círculos do MSP em todo o mundo e também a especialistas nos assuntos em pauta, e são finalizadas dias antes do início das reuniões, ficando disponíveis gratuitamente pela internet, no site do Global Health Watch (www.ghwatch.org). São também distribuídas nas reuniões para os representantes de países e integrantes de outros movimentos sociais.

A participação dos círculos nacionais na elaboração dos comentários agrega exemplos concretos de como tais políticas atingem os diferentes países e valoriza as questões locais, evidenciando as relações existentes entre ações locais e globais. Já a colaboração de especialistas, que não fazem parte do MSP necessariamente, garante uma fundamentação teórico-conceitual sólida, contribuindo para a credibilidade da discussão. O envolvimento de diversos segmentos contribui para a formação de uma grande rede colaborativa, que busca representara diversidade das realidades regionais, nacionais e locais. 
Durante as reuniões, os watchers (como são chamados os observadores) realizam ações de advocacy com os representantes dos países e de organizações da sociedade civil e tomam notas sobre as discussões mais importantes. Essas notas, posteriormente, ficam disponíveis para consulta, possibilitando, assim, que mais pessoas tenham acesso às discussões realizadas no âmbito das reuniões da OMS, o que antes ficava restrito a determinados atores. Os watchers também podem ler em plenária as análises críticas que ajudaram a elaborar acerca dos temas da agenda, levando aos delegados - representantes dos EstadosMembros - a voz dos movimentos sociais. No entanto, essa participação é bastante restrita, já que cada entidade pode fazer apenas uma declaração por tópico, e essa declaração é feita após toda a discussão, não tendo capacidade de interferir nos rumos da discussão.

\section{A experiência da participação no WHO Watch}

A seguir, serão apresentadas as experiências de observação, realizadas pela primeira autora deste artigo,na $53^{\text {a }}$ Reunião do Conselho Diretor da Organização Pan-Americana da Saúde (Opas) e na 136 ${ }^{\mathrm{a}}$ Reunião do Conselho Executivo da OMS, e no apoio à equipe de watchers, na $67^{\mathrm{a}}$ Assembleia Mundial da Saúde.

As atividades do WHO Watch são divulgadas pelos canais do MSP, como páginas nas redes sociais e listas de $e$-mails, e foi através de um desses $e$-mails que a autora soube da possibilidade de atuar como observadora. Os watchers presenciais dos eventos regionais geralmente são nacionais dos países daquela região, já aqueles que participam do projeto nos eventos da OMS costumam ser de diversos países. A proximidade com Genebra facilita a participação de ativistas europeus. $\mathrm{Na} 53^{\mathrm{a}}$ Reunião do Conselho Diretor da Opas, havia ativistas do Brasil, do Canadá, dos Estados
Unidos da América (EUA), da Índia e do México. Já o $136^{\circ}$ Conselho Executivo da OMS contou com a participação de ativistas da Alemanha, da Austrália, da Bélgica, do Brasil, dos EUA, da França, da Índia e da Itália.

A experiência de apoio ao time de watchers que atuaram na $67^{\mathrm{a}}$ Assembleia Mundial da Saúde, ocorrida em Genebra, no mês de maio de 2014, ocorreu de maneira virtual. O trabalho consistiu em organizar as notas que estavam sendo tomadas nas reuniões - uma das tarefas de um watcher é anotar os principais pontos da discussão de cada item da agenda, de maneira que uma pessoa que leia esse material seja capaz de entender o que foi encaminhado sobre aquele assunto. Nas reuniões da OMS, em um único turno, podem ser discutidos vários itens da pauta, além disso, as anotações costumam usar abreviaturas e outras ferramentas que ajudem o watcher a tomar nota de modo rápido para não perder nenhum ponto da discussão. Assim, a função do apoio é revisar e organizar essas notas, utilizando, para tanto, ferramentas virtuais, como Skype. O grupo de trabalho do WHO Watch mantém um canal no Skype, no qual são disponibilizadas todas as declarações realizadas em cada sessão em tempo real, possibilitando a interação com os watchers e o acompanhamento das discussões.

Durante a $53^{\text {a }}$ Reunião do Conselho Diretor da Opas (CD53), em setembro de 2014, na cidade de Washington, Estados Unidos, a experiência foi presencial, como integrante da equipe de watchers. No entanto, um Watch começa muito antes da semana de reuniões acontecer. Após a manifestação de interesse do observador em participar presencialmente, para a coordenação do projeto,a primeira atividade é organizar, junto ao círculo nacional de origem - nesse caso, o Movimento pela Saúde dos Povos Brasil (MSP Brasil)-, uma lista de itens prioritários baseada na agenda prévia do CD53. Cada círculo regional ou nacional do MSP elabora essa lista de prioridades, a partir da qual é construída uma lista com tópicos considerados prioritários e para os quais o MSP produzirá comentários com análises críticas 
para serem distribuídas aos delegados presentes no CD53 e disponibilizados na página da internet do WHO Watch. Itens prioritários são assuntos considerados muito importantes para o círculo, mas também são tópicos sobre os quais os colaboradores do MSP tenham capacidade e possibilidade de analisar, discutir e propor alternativas.

A questão do tempo é relevante, pois o trabalho dos ativistas do WHO Watch é feito com base nos documentos de trabalho disponibilizados pelas agências internacionais. No caso do CD53, a maior colaboração do MSP Brasil foi feita no tema da Cobertura Universal de Saúde, cujo documento de trabalho, o CD53/5 (Estratégia para o Acesso Universal à Saúde e à Cobertura Universal de Saúde), foi divulgado apenas três semanas antes do início da Reunião do Conselho. Dessa forma, além de conhecimento específico sobre o tema, o ativista, por vezes, precisa ter tempo disponível para elaborar uma análise cuidadosa em um curto intervalo de tempo. Para as reuniões da Opas, os comentários sobre os temas são disponibilizados pelos colaboradores do WHO Watch geralmente em espanhol e inglês, de maneira que, entre a elaboração, a revisão, a tradução e a impressão do comentário, há pouco tempo hábil. No caso específico do documento de trabalho CD53/5, ele ainda viria a ser modificado, e uma nova versão, com alterações importantes, foi divulgada faltando menos de uma semana para o início da reunião, cabendo, nessa situação, aos observadores que iriam atuar presencialmente em Washington, a edição e a formatação final do comentário em poucos dias ou horas antes da reunião.

Concomitantemente à elaboração do comentário, foram feitas reuniões virtuais para apresentação aos novos watchers sobre o funcionamento dos órgãos diretores da Opas e a inserção do WHO Watch nesse contexto. Essa preparação foi finalizada em Washington, com uma oficina de orientação de dois dias, para discussão de temas como governança na Opas/ OMS e estratégias de advocacy. Esses dois dias também foram usados para a finalização de comentários ainda pendentes e para elaboração de declarações a serem lidas durante o CD53. A participação da sociedade civil está prevista nas reuniões dos órgãos diretores da Opas e é realizada através de uma intervenção por tópico, após a discussão realizada pelos representantes oficiais dos Estados-Membros. A declaração não pode ter mais de 300 palavras e deve ser entregue com antecedência ao administrativo da Agência, expressando o posicionamento da organização ou entidade que o redigiu, mas não permitindo uma maior interação e discussão, limitando-se apenas a uma manifestação crítica.

No CD53, as principais atividades ocorreram na sala A do prédio da Opas, à qual os delegados dos países, o corpo técnico da Opas e da OMS e os representantes de organizações não governamentais tinham livre acesso, ficando estes últimos ao fundo da sala. O MSP não é uma organização não governamental, é um movimento, mas teve acesso ao CD53 através de parceria com a Medicus Mundi International, organização não governamental que mantém relações oficiais com a OMS. Estavam presentes, no CD53, doze organizações não governamentais com relações oficiais com a OMS, dez organizações não governamentais com relações oficiais com a Opas e sete organismos internacionais ${ }^{19}$. Entre as organizações não governamentais, havia representações de estudantes e profissionais, coletivos de usuários, organizações que atuam no combate a determinadas doenças (como câncer e Alzheimer), a Federação Latino-Americana da Indústria Farmacêutica e a Federação Internacional da Indústria de Medicamentos.

A proximidade física com os delegados de países facilita a abordagem, que ocorre principalmente nos intervalos entre as sessões, quando são entregues os comentários elaborados sobre os tópicos da agenda. Muitos delegados demonstraram bastante interesse nos comentários, havendo aqueles que julgavam importante ter subsídios elaborados por movimentos sociais e mesmo representantes de países com pequenas delegações - às vezes, 
apenas um ou dois delegados - que diziam usar o material para ajudar a aprofundar o conhecimento em determinados temas. Aliás, esse foi um detalhe que chamou a atenção: enquanto a delegação dos EUA contava com 25 pessoas, algumas das quais especialistas em temas específicos, havia delegações de países com apenas um membro. O grupo do WHO Watch que atuou no CD53 e os demais ativistas do MSP elaboraram comentários para cinco temas: Estratégia para o Acesso Universal à Saúde e a Cobertura Universal de Saúde, Plano de Ação sobre Deficiência e Reabilitação, Plano de Ação sobre Saúde Mental, Plano de Ação sobre Saúde em Todas as Políticas e Estratégia sobre a Legislação Relacionada com a Saúde. Foram feitas declarações sobre três temas: Estratégia para o Acesso Universal à Saúde e a Cobertura Universal de Saúde, Plano de Ação sobre Saúde Mental e Estratégia sobre a Legislação Relacionada com a Saúde.

A $136^{\mathrm{a}}$ Reunião do Conselho Executivo da OMS (EB136) ocorreu de 26 de janeiro a 3 de fevereiro de 2015, na sede da OMS, em Genebra, na Suíça. Alguns elementos do Watch em Genebra foram semelhantes ao de Washington, já detalhados acima, pois seguem a mesma lógica. Diferentemente do Conselho Diretor da Opas, que é regional, o Conselho Executivo (EB) é global, por isso também seu Watch envolve ativistas de todo o mundo. Diversas redes compõem o WHO Watch e suas contribuições se dão tanto via internet (elaboração dos comentários, auxílio com as notas de cada reunião, por exemplo) quanto presencialmente: o workshop de orientação para o EB136 foi realizado na sede de uma organização independente, em Genebra,reunindo diversos representantes da sociedade civil, tendo por objetivo definir estratégias de advocacy e lobby para o EB136. Essa reunião foi uma oportunidade de conhecer ativistas de diferentes backgrounds e também de perceber como os diversos membros desse universo heterogêneo chamado de 'sociedade civil' agem e interagem. No workshop, realizado de 21 a 25 de janeiro, foram finalizados os comentários sobre os itens da agenda do Conselho Executivo. Foram também elaboradas as declarações sobre os assuntos prioritários,a serem lidas nas sessões do EB136, e definidas estratégias de ação do grupo de watchers. A formação envolveu diversos ativistas (professores universitários, membros de organizações, profissionais de organismos internacionais), que falaram sobre a constituição da OMS, seu histórico, seu funcionamento, sua atuação na governança global em saúde e o papel do WHO Watch nesse contexto.

Diferentemente do Conselho Diretor da Opas, em um EB, as representações da sociedade civil permanecem a maior parte do tempo em galerias superiores, separadas das delegações dos países. Isso dificulta o contato com os delegados. Mesmo que a maior parte dos encontros seja feita no intervalo entre as sessões e que os espaços de descanso sejam comuns a todos (cafeterias para o almoço, coffee-break no saguão principal), o simples fato de não haver nenhum contato durante as sessões, nem mesmo visual, dificulta as aproximações e as conversas necessárias. Além disso, sendo um evento global, o número de delegações é muito maior, sendo mais difícil identificar quem é quem. Durante um turno do CD53, por exemplo, já era possível identificar uma parte considerável não apenas dos delegados de cada país, mas também de delegados de organizações da sociedade civil.

No EB136, foram visíveis as diferenças entre as nações, não apenas com relação ao número de delegados por país, mas também no que diz respeito à composição das delegações. Enquanto alguns Estados, geralmente os mais ricos, contam com delegados com larga experiência no campo da governança global em saúde, outros não dispõem de pessoal com esse perfil, tornando os processos de tomada de decisão mais difíceis de serem influenciados.

O grupo do WHO Watch que atuou no EB136 e os demais ativistas das redes do MSP 
elaboraram comentários relacionados a 36 tópicos e fizeram doze declarações.

Com relação à composição das delegações que representavam a sociedade civil no EB136, havia 51 organizações não governamentais em relações oficiais com a OMS7 - organizações de usuários, grupos de pressão por investimento em pesquisas de determinadas enfermidades, associações de estudantes e profissionais de diversas áreas, a Federação Internacional da Indústria de Medicamentos e a Global Health Council, Inc. De acordo com sua página na Internet, o Global Health Inc. é

composto por membros da organização e centenas de indivíduos - todos comprometidos com a missão de melhorar a saúde em nível mundial através do aumento de investimentos, políticas robustas e o poder da voz coletiva20(1).

Integram o Global Health Council Inc. 'organizações de desenvolvimento internacional sem fins lucrativos (Organizações Não Governamentais - ONGs)', organizações internacionais de desenvolvimento com fins lucrativos, corporações/empresas privadas, organizações baseadas na fé, universidades, fundações e indivíduos ${ }^{20}$. Faziam parte da delegação do Global Health Council Inc., no EB136, três representantes da Nestlé e três da Rabin Martin, uma empresa de consultoria que "ajuda seus clientes a serem líderes na melhoria da saúde e no acesso a tecnologias de saúde global"21(1) e que tem entre seus clientes a Fundação Bill \& Melinda Gates, a Johnson \& Johnson e a Merck \& Co., Inc. ${ }^{21}$.

\section{A análise da participação no WHO Watch}

A experiência do WHO Watch evidencia a governança global em saúde como um processo em rede cada vez mais complexo formado por diversos atores, como Estados Nacionais, organismos bi e multilaterais, sociedade civil, corporações, entidades filantrópicas, universidades, entre outros, de forma que os mais diversos interesses estão envolvidos, o que reforça a necessidade de uma sólida liderança.

A OMS mantém-se como uma referência para a formulação de políticas de saúde, portanto, suas recomendações e seus pareceres técnicos possuem prestígio no cenário internacional, o que a torna um espaço em disputa ${ }^{22}$. As relações de poder desenvolvidas em seu interior são flagrantemente desiguais. Algumas nações dispõem de recursos, financeiros e humanos, e são capazes de se articular de modo a influenciarem fortemente as decisões a serem tomadas. Outros países têm condições de enviar para as reuniões apenas pequenas delegações, o que inviabiliza que os delegados conheçam profundamente todos os tópicos que são discutidos no âmbito da OMS e da Opas ou mesmo que influenciem as discussões - seja através de lobby ou de doações voluntárias a projetos escolhidos.

Da mesma forma, ainda que a participação da sociedade civil esteja prevista no regramento da OMS, o custo para enviar representantes para os locais nos quais ocorrem as reuniões torna a atuação nesses espaços difícil ou quase impossível para muitas organizações. A pouca agilidade com que determinadas discussões ocorrem também é um ponto a destacar, mostrando que há temas difíceis de serem tratados, como as questões de gênero, por exemplo - em função de fatores religiosos e culturais -, ou questões que desafiem interesses dos países ricos. Pega e Veale ${ }^{23}$ demonstram isso ao analisar a Comissão de Determinantes Sociais em Saúde da OMS, onde não há inclusão da temática de gênero como algo que influencia a saúde da população, contribuindo para a marginalização e a negligência da saúde das mulheres e, mais fortemente, das pessoas trans.

Além de todos esses fatores, é importante considerar, também, no momento atual, que o processo em curso de Reforma da OMS acontece em um momento único para a Agência, devido à erosão do seu protagonismo mundial 
em matéria de saúde, às fragilidades de seu sistema de financiamento, ao conflito de interesses de seu corpo de especialistas, às dificuldades de comunicação e aos problemas de governança interna desde a década de $1990^{24}$. A experiência do WHO Watch demonstrou que tal Reforma precisa trazer de volta à OMS e a seus Estados-Membros, prioritariamente, o controle do gerenciamento das ações desenvolvidas no âmbito da governança global em saúde, assim como corrigir inequidades com relação à participação dos países. Nesse contexto, a sociedade civil é um importante agente de mudanças, trazendo a voz das comunidades para dentro da OMS e repercutindo suas discussões para além de seus membros e de seu corpo técnico. Narayan ${ }^{25}$ aponta o trabalho do MSP como entidade que pressiona para que temas sobre determinantes sociais em saúde estejam na agenda global, levando a um nível com maior amplitude as necessidades sociais.

Outra questão importante no atual quadro da OMS é sua relação com agentes não estatais,que, ao longo das últimas décadas, vem aumentando, tanto em quantidade de agentes envolvidos como de atividades ${ }^{26}$. Se, antes, a OMS era vista como a "autoridade maior e porta-voz da saúde no mundo"27(5), agora encontra-se em uma rede de agências que compartilham com ela a governança global em saúde. Também nesse aspecto a participação social entra como fiscalizadora das ações que levam o nome da Agência, mas que intervêm na realidade por outras lógicas que não a da solidariedade global, podendo colaborar para o fortalecimento da autonomia da OMS frente aos desafios sanitários internacionais. Tal posicionamento requer grande preparo dos movimentos sociais devido a condições institucionais que dificultam o acesso, a permanência e a influência da participação social nas reuniões. Como exemplo, pode-se citar o pouco tempo de antecedência com que são divulgados os documentos-base das reuniões e a dificuldade geográfica de chegar até as assembleias. Nesse sentido,faz-se necessário negociar e lutar para que ocorra, sempre mais, a queda das barreiras que regulam o direito humano à informação e à saúde.

\section{Considerações finais}

A sociedade civil é capaz de influenciar a curto, médio e longo prazos os processos decisórios da OMS e de suas agências regionais através de diferentes mecanismos e estratégias. Os movimentos sociais trazem uma visão crítica sobre as discussões realizadas por esses órgãos oficiais, promovendo, também, a divulgação desses debates e de seus desdobramentos para além dos espaços governamentais.

A participação de discentes e docentes em movimentos sociais que trabalhem com a temática da governança global em saúde exerce influência na formação de futuros profissionais que poderão exercer cargos de liderança nos governos dos países membros dessas agências e, também, fazer parte do corpo técnico dos organismos internacionais. Percebe-se, então, a importância da inclusão de estudos e momentos de prática sobre saúde global na formação em nível superior, de graduação e pós-graduação, a fim de proporcionar referências e subsídios para o exercício profissional em um mundo cada vez mais globalizado. Mesmo que não atuem diretamente com a governança global, é fundamental reconhecer a interação entre o agir local e as influências recíprocas com o pensamento sistêmico mundial.

A atuação de profissionais que entendam a saúde como um direito em órgãos governamentais e agências intergovernamentais é uma maneira de mudanças sociais. A participação nas atividades do WHO Watch permite às novas gerações um conhecimento prático de como funcionam os processos da governança global em saúde e também uma maior aproximação e familiarização com temas importantes e atuais no campo da saúde global.

Por fim, urge que sejam feitas e estimuladas, com apoio financeiro, pesquisas, reflexões, participações e intervenções, que possibilitem maior apropriação desses mecanismos de 
saúde global e que possam contribuir para a (re)construção da OMS e de outras Agências do Sistema das Nações Unidas, a partir das demandas populares de saúde, a fim de que as prioridades de um maior contingente de pessoas pautem as reuniões e as decisões nacionais e internacionais.

\section{Referências}

1. People's Health Movement. Global Health Watch 4: An Alternative World Health Report. London: Zed Books; 2014.

2. Matida A. Arroz, feijão, saúde, educação: Política Pública de Saúde no Brasil. Ciênc. Saúde Colet. 2011; 16(3):1668-1668.

3. Rhodes A, Varoufakis Y. The Global Minotaur: America, the True Origins of the Financial Crisis and the Future of the World Economy. London: Zed Books; 2011.

4. Cueto M. Saúde Global: uma breve história. Rio de Janeiro: Fiocruz; 2015

5. World Health Organization. Declaration of Alma-Ata [internet]. 1978. [acesso em 2019 abr 2]. Disponível em: www.who.int/publications/almaata_declaration_en.pdf.

6. United Nations. Millenium Declaration [internet]. Nova York, 2000. [acesso em 2019 fev 18]. Disponível em: www.un.org/millennium/declaration/ares552e.htm.

7. World Health Organization. 136th Executive Board

\section{Colaboradores}

Rocha CMF (0000-0003-3281-2911)*, Martins MR (0000-0001-5582-1605)* e Farias MA (0000-0001-6622-9949)* contribuíram igualmente na elaboração do manuscrito.

[internet]. Liste des membres et autres participants [data desconhecida]. [acesso em 2019 fev 18]. Disponível em: http://apps.who.int/gb/ebwha/pdf_files/ EB136/B136_DIV1Rev2-en.pdf.

8. United Nations. Health in the post-2015 UN development agenda: Thematic Think Piece [internet]. [local desconhecido]: UN; 2012. 17 p. [acesso em 2020 jan 15]. Disponível em: https://www.un.org/millenniumgoals/pdf/Think\%20Pieces/8_health.pdf.

9. United Nations. Plataforma Agenda 2030 [internet]. [acesso em 2019 abr 2]. Disponível em: http://www. agenda2030.com.br/.

10. Global Health Watch. Global Health Watch 3. Londres: Zed Books; 2011.

11. Kickbusch I, Lister G. European Perspectives on Global Health: a policy glossary. Brussels: European Foundation Centre; 2006.

12. Martins MR. Saúde para Todos: A participação social na Governança Global em Saúde [trabalho de conclusão de curso]. Porto Alegre: Universidade Federal do Rio Grande do Sul; 2016. 31 p.
${ }^{*}$ Orcid (Open Researcher and Contributor ID). 
13. Kickbusch I, Berger C. Diplomacia da saúde global. Rev. Eletr.Comun. Inf.Inov. Saúde. 2010; 4(1):19-24.

14. Fidler DP. The Challenges of Global Health Governance. New York: Council on Foreign Relations Press; 2010.

15. Buss PM, Ferreira JR. Ensaio crítico sobre a cooperação internacional em saúde. Reciis. 2010; 4(1):93105.

16. Gostin LO, Mok EA. Grand challenges in global health governance. Br Med Bull. 2009; 90:7-18.

17. People's Health Movement. People's Charter for Health [internet]. Bangladesh: [data desconhecida]. [acesso 2019 fev 19]. Disponível em: https://phmovement. org/wp-content/uploads/2018/06/phm-pch-english. pdf.

18. Legge D. Social Movement Activism. 2013. [Não publicado].

19. Pan American Health Organization. 53rd Directing Council. List of Participants[internet]. 2014. [acesso 2019 fev 18]. Disponível em: www.paho.org/hq/index.php?option=com_docman\&task=doc_downloa $\mathrm{d} \&$ gid $=27437$ Itemid=270\&lang=en .

20. Global Health Council. Global Health Council: Members [internet]. [acesso em 2019 fev 18]. Disponível em: http://globalhealth.org/about-us/member-directory/.

21. Rabin Martin. About Us - Rabin Martin [internet]. [acesso em 2019 abr 2]. Disponível em: http://rabinmartin.com/our-firm/passion/.

22. Brown TM,Cueto M,Fee E. A transição de saúde pública 'internacional' para 'global' e a Organização Mundial da Saúde. Hist. cienc. saude-Manguinhos. 2006; 13(3):623-647.

23. Pega F, Veale JF. The Case for the World Health Organization's Commission on Social Determinants of Health to Address Gender Identity. Am. J. Publ. Health. 2015; 105(3):e58-e62.

24. Ventura D, Perez FA. Crise e reforma da Organização Mundial da Saúde. Lua Nova. 2014; 92:45-77.

25. Narayan R. The role of the People's Health Movement in putting the social determinants of health on the global agenda. Health Promot. J. Austral. 2006; 17(3):186-188

26. Martins MR. Histórias da saúde global: a Organização Mundial da Saúde e a cooperação com atores não-estatais [dissertação]. Porto Alegre: Universidade Federal do Rio Grande do Sul; 2015. 98 p.

27. World Health Organization. A64/10 - Report of the review committee on the functioning of the international health regulations (2005) in relation to pandemic (H1N1). Genebra: OMS; 2009.

Recebido em 13/04/2019

Aprovado em 10/09/2019

Conflito de interesses: inexistente

Suporte financeiro: não houve 